\title{
50 Anos de Abem e seu Compromisso com a Residência Médica
}

\author{
50 Years of Abem and its Commitment to \\ Medical Residency
}

\author{
Pedro Tadao Hamamoto Filhol \\ Arthur Hirschfeld Danila ${ }^{I I}$ \\ Túlio Cícero Franco Farret ${ }^{I I I}$ \\ Diego Millán Menegotto ${ }^{I V}$ \\ Thiago Henrique dos Santos Silvav
}

\section{PALAVRAS-CHAVE: \\ - Residência Médica; \\ - Educação Médica; \\ - Médicos-Residentes; \\ - Avaliação.}

\section{KEYWORDS:}

- Medical Residency;

- Medical Education;

- Medical Residents;

- Evaluation.
Recebido em: 17/11/2012

Reencaminhado em: 07/01/2013

Aprovado em: 09/01/2013

REVISTA BRASLLEIRA DE EDUCAÇ̄̃o MÉDICA

\section{PREZADO EDITOR,}

São muito oportunos os últimos editoriais da Revista Brasileira de Educação Médica. Ferreira sumarizou a trajetória da Associação Brasileira de Educação Médica (Abem) em seus 50 anos, destacando sua influência nas políticas nacionais de educação e saúde, mobilizando a participação de escolas, docentes, discentes e serviços de saúde ${ }^{1}$. Já Afonso apresentou o Projeto de Preceptoria para Residência Médica como um marco na formação de especialistas, demonstrando que a Abem, ao protagonizar o processo, poderá liderar uma "onda" de capacitação de preceptores².

Ao longo de 2011 e 2012, a Abem modificou seu estatuto e criou o cargo de coordenadores médicos-residentes regionais, garantindo-lhes representação em seu Conselho de Administração. Por ocasião do $50^{\circ}$ Congresso Brasileiro de Educação Médica, realizado na Faculdade de Medicina da Universidade de São Paulo, a Abem elegeu seu primeiro grupo de coordenadores médicos-residentes regionais. Consideramos o fato uma grande demonstração do compromisso da Abem com a residência médica - o que ocorre, justamente, quando de seu $50^{\circ}$ aniversário.

A residência médica tem importância ímpar na formação médica. É o melhor instrumento para inserção do médico no mundo de trabalho. E é neste período que o médico tem a oportunidade de, sob supervisão, combinar a aquisição de conhecimentos teóricos com a experiência clínica.

Desenvolvida no Brasil desde a década de 1940, a residência médica sempre enfrentou obstáculos para se estruturar, consolidar e avançar. Em 2003, Nunes resumia em quatro aspectos os problemas da residência: avaliação, necessidade, acesso e financiamento ${ }^{3}$. Passados quase dez anos, podemos observar avanços, mas há ainda muito o que enfrentar.

Uma avaliação sistemática dos programas de residência médica ainda precisa ser estruturada. A Comissão Nacional de Residência Médica (CNRM) tem investido neste aspecto, em especial neste ano em que se mobilizaram avaliadores de todo o País para o recredenciamento dos programas. Apesar de todo o mérito dos trabalhos da CNRM, obviamente não se pode avaliar detalhadamente cada programa. É necessário que cada instituição incorpore a cultura de avaliação de seus programas e de seus residentes. Muito dessa avaliação tem ficado sob a responsabilidade das sociedades de especialidades quando do pleiteio do título de especialista. Para tanto, uma avaliação sistemática de aspectos cognitivos, habilidades e competências profissionais deve ser desenvolvida e aprimorada em cada programa de residência.

\footnotetext{
I Universidade Estadual Paulista "Júlio de Mesquita Filho", Botucatu, SP, Brasil.

"Universidade de São Paulo, São Paulo, SP, Brasil.

III Hospital Fêmina, Grupo Hospitalar Conceição, Porto Alegre, RS, Brasil.

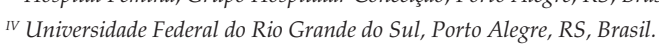

${ }^{v}$ Universidade Federal de Pernambuco, Recife, PE, Brasil.
} 
Com relação à necessidade, impera no País a desigualdade de distribuição de programas e bolsas, que se concentram nas regiões Sul e Sudeste. O Pró-Residência (Programa de Incentivo à Formação de Especialistas em Áreas Estratégicas), iniciativa conjunta dos ministérios da Saúde e Educação, fomentou a criação de programas com carência de profissionais em determinadas regiões geográficas do País. Ainda assim, muitas vagas oferecidas continuam ociosas. Se o Brasil precisa equacionar políticas educacionais e de saúde, deve buscar enfaticamente o investimento em programas de residência médica.

Sobre o acesso aos programas, houve avanços significativos, principalmente com a Resolução no 8 de 2004 da CNRM, que introduziu um componente prático com peso de $40 \%$ a $50 \%$ nos concursos de seleção (sendo esta uma fase opcional, a critério da instituição). Com a adoção de provas práticas nos concursos de tradicionais instituições de ensino do País, observa-se a valorização de atividades clínicas pelos estudantes de graduação. Por outro lado, a indiscriminada abertura de novos cursos e escolas médicas sem o proporcional aumento do número de vagas de residência está por criar no País um grande contingente de médicos sem o melhor preparo, considerando a não terminalidade do curso médico (embora a não terminalidade do curso não seja a opinião formal da Abem e de muitos professores de Medicina) e o crescente volume de conhecimento científico necessário a uma prática médica de qualidade.

Finalmente, quanto ao financiamento, avanços têm sido observados. Vale destacar as atividades de classe dos médicos-residentes, representados pela Associação Nacional dos Médicos Residentes, que, mobilizando residentes de todo o País, tem lutado por melhores valores para as bolsas. Ainda assim, o órgão regulamentador da residência (MEC) não é o mesmo que subsidia a maior parte das bolsas (a cargo das secretarias estaduais de saúde e das instituições), o que se torna fonte potencial de conflitos.

Neste cenário, é promissor que a Abem conte com maior participação de médicos-residentes em seus conselhos regionais e nacional. Propondo-se a Abem ser a principal protagonista de melhorias da educação médica brasileira ao in- fluenciar políticas públicas de educação e saúde, incluir os residentes em seu organograma significa ampliar o espaço das pautas de discussão para a residência médica. Significa a possibilidade de disseminar entre os residentes uma discussão ainda mais aprofundada e embasada nas melhores teorias educacionais - articulada com a vivência singular do médico nesta etapa de sua formação.

Porém também há desafios. Das oito regionais da Abem, que deveriam eleger um total de 16 representantes (titulares e suplentes), apenas as regionais São Paulo, Sul I e Nordeste elegeram representantes - sendo que, dos cinco eleitos, dois deverão concluir seus programas no início de 2013. Precisamos articular as regionais com os residentes, sensibilizando-os para a necessidade de se engajarem - o que significa, na verdade, a oportunidade de qualificar a formação de especialistas no País.

O grupo eleito, que subscreve esta carta, deseja contribuir com as discussões e com a melhoria dos problemas sumariamente apontados. É o nosso compromisso com a Abem, com a própria residência médica, com a educação médica e com a saúde do País.

\section{REFERÊNCIAS}

1. Ferreira JR. 50 Anos da Abem. Rev Bras Educ Med 2012; 36(3):291-2.

2. Afonso DH. O Compromisso da Abem com a Residência. Rev Bras Educ Med 2012; 36(2):151-2.

3. Nunes MPT. Residência Médica no Brasil - Situação Atual e Perspectivas. Cad ABEM 2004; 1:30-2

\section{CONFLITO DE INTERESSES}

Declarou não haver.

\section{ENDEREÇO PARA CORRESPONDÊNCIA}

Pedro Tadao Hamamoto Filho

Departamento de Neurologia, Psicologia e Psiquiatria, Faculdade de Medicina de Botucatu-Unesp

Distrito de Rubião Jr, s/n ${ }^{\circ}$ - Botucatu

CEP 18618-970 - SP

E-mail: pthamamotof@hotmail.com 